\title{
Consistent declining trends in stroke mortality in Brazil: mission accomplished?
}

Tendências decrescentes constantes na mortalidade por AVE no Brasil: missão cumprida?

Valéria M. A. Passos ${ }^{1,2}$, Lenice H. Ishitani3,4, Glaura C. Franco ${ }^{5}$, Gustavo C. Lana ${ }^{5}$, Daisy M. X. Abreu ${ }^{4}$, Maria de Fatima Marinho, ${ }^{2,4}$ Elisabeth B. França ${ }^{2,4}$

\begin{abstract}
Stroke mortality rates are declining in Brazil, but diferences among regions need to be better investigated. The age-adjusted stroke mortality trends among adults (30-69 years-old) from Brazilian regions were studied between 1996 and 2011. Method: Data were analyzed after: 1) reallocation of deaths with non-registered sex or age; 2) redistribution of garbage codes and 3) underreporting correction. A linear regression model with autoregressive errors and a state space model were fitted to the data, aiming the estimation of annual trends at every point in time. Results: Although there were high values, a steady decrease of rates was observed. The decreasing trends among all regions were statistically significant, with higher values of decline among the Northeast and Northern regions, where rates were the highest. Conclusion: Standardized methodology use is mandatory for correct interpretation of mortality estimates. Although declining, rates are still extremely high and efforts must be made towards prevention of stroke incidence, reduction of case-fatality rates and prevention of sequelae.
\end{abstract}

Key-words: stroke; mortality rate; health inequalities.

RESUMO

Objetivos: As taxas de mortalidade por acidente vascular encefálico (AVE) estão em declínio no Brasil, mas diferenças entre as regiões precisam ser melhor investigadas. Foram analisadas as tendências de mortalidade por AVE ajustadas por idade em adultos (30-69 anos) de regiões do Brasil, entre 1996 e 2011. Método: Análise realizada após realocação dos óbitos sem registro de sexo ou idade; redistribuição de códigos mal definidos e correção do subregistro. Modelos de regressão linear e de espaço de estados foram utilizados visando estimativas de tendências anuais em todos pontos no tempo. Resultados: Observou-se redução de cerca de 50\% nas taxas de mortalidade em todas as regiões, para homens e mulheres, com maiores declínios nas regiões Norte e Nordeste, onde as taxas eram as mais elevadas. Conclusão: Usar metodologia padronizada é fundamental para interpretação correta das estimativas de mortalidade. Esforços devem ser feitos para prevenção da incidência de AVE, redução das taxas de letalidade e prevenção de sequelas.

Palavras-chave: acidente vascular cerebral; mortalidade; desigualdades em saúde.

Stroke is the second leading cause of death in Brazil and worldwide $^{1}$ and trends in stroke mortality rates may be analyzed as a proxy of social economic differences among countries and regions. A systematic review of population-based studies showed a divergent, statistically significant difference trend in stroke incidence rates, from 1970 to 2008 . It was observed a $42 \%$ decrease in stroke incidence in high income countries in contrast to a more than $100 \%$ increase in this incidence in middle and low income countries ${ }^{2}$. There is a ten-fold difference in mortality rates for stroke between the most-affected and the less-affected countries. Moreover, national per capita income has been pointed out as the strongest predictor of stroke mortality even after adjusting for cardiovascular risk factors ${ }^{3}$.

In Brazil, there is evidence of declining mortality from stroke in São Paulo since the $1970 s^{4}$ and all over the country since the $1980 s^{5}$, but the magnitude of the mortality rates and its decline, as well as the differences among the regions of the country need to be better investigated. From 1979 to 1996, among Brazilian adults aged 30 or more years old, despite the high values, the age-adjusted death rate for stroke dropped significantly ( $\mathrm{p}<0.001)$ from 200 to 164 deaths/100,000 population in men and from 168 to 130 deaths/100,000 population in women ${ }^{6}$.

\footnotetext{
Universidade Federal de Minas Gerais, Programa de Pós-Graduação em Saúde do Adulto, Belo Horizonte MG, Brasil;

2 Universidade Federal de Minas Gerais, Programa de Pós-Graduação em Saúde Pública, Belo Horizonte MG, Brasil;

3Secretaria Municipal de Saúde de Belo Horizonte, Gerência de Epidemiologia e Informação, Belo Horizonte MG, Brasil;

¿Universidade Federal de Minas Gerais, Grupo de Pesquisa em Epidemiologia e Avaliação de Saúde, Belo Horizonte MG, Brasil;

5 Universidade Federal de Minas Gerais, Departamento de Estatística, Belo Horizonte MG, Brasil.

Correspondence:Valéria M A Passos;Av. Alfredo Balena 190/sala 807;30190-100 Belo Horizonte MG, Brasil; E-mail: passos.v@gmail.com

Conflict of interest: There is no conflict of interest to declare.

Financial support: Ministério da Saúde, Fundo Nacional de Saúde (Processo 25000214175/2012-75 - Termo de Cooperação 248/2012).

Received 06 August 2015; Received in final form 02 December 2015; Accepted 15 March 2016.
} 
Mortality is a measure of incidence of deaths in the total population at risk and its frequency depends both on the incidence of the disease and its case-fatality ratio, the proportion of death among those with the disease. Survival to stroke is highly dependent on medical care, which seems to be improving in the country. In the beginning of the ' 80 s, a one-year study in all hospitals and emergency care units in the city of Salvador revealed an extremely high 30-day case fatality rate (80.7\%), probably consequence of poor access to health preventive and medical facilities, mainly hypertension care and emergence assistance ${ }^{7}$. In 2003-2004, the only two Brazilian population-based studies, in small cities (75,000 inhabitants) of the states of Sao Paulo ${ }^{8}$ and Santa Catarina ${ }^{9}$, observed a 30 -day case fatality rate of less than $20 \%$, similar to that observed in developed countries ${ }^{2}$. Among the population of Joinville city, compared with data from 1995, it was observed around 30\% decrease in incidence, mortality and 30-day case fatality ratio for stroke ${ }^{9}$. It is noteworthy that these estimates cannot be generalized to the whole country, as these studies were performed in the two most developed Brazilian regions.

Stroke incidence can be prevented to a large extent by health policies toward reduction of its main risk factors, as hypertension, diabetes, smoking, unhealthy diet and lack of physical activity. Prevention of premature deaths is one of the main objectives of health policies and declining trends on mortality and case fatality rates reflect social and medical improvement over time.

In order to investigate if these good trends have come to stay, this work studies the stroke mortality among the Brazilian adults up to now. Moreover, the stroke mortality trends among the regions of the country are also evaluated, since inequalities may be hidden by aggregate data.

\section{METHOD}

Deaths from all types of cerebrovascular disease were classified using the underlying cause codes I60-I69 according to the International Classification of Diseases - Tenth Revision (ICD-10). Data from all deaths that occurred between 1996 and 2011 among individuals aged between 30 and 69 years were obtained from the Brazilian Mortality Information System (SIM, Sistema de Informação sobre Mortalidade $)^{10}$, which provides underlying cause of death, date, local of death and selected characteristics of deceased.

The crude number of notified deaths were corrected according to the following steps: 1) deaths with non-registered sex or age were reallocated pro-rata according to registered sex and age; 2) redistribution of garbage codes, that is, deaths from all other ICD chapters assigned to causes that cannot or should not be considered underlying causes of death, by sex and region ${ }^{1}$ and 3 ) redistribution of ill-defined causes of deaths (ICD 10 XVIII chapter) ${ }^{11}$ (Table 1).

Finally, as considerable differences exist in the degree of completeness of the vital registration among the Brazilian regions, the proportion of all deaths that is registered for the population covered by the vital registration system has been estimated separately. The "Rede Intergerencial de Informações para a Saúde” (RIPSA) coverage estimates between 1996 and 2011 were used to perform corrections of underreporting for both sexes ${ }^{12}$, and estimated by sex. Underreporting correction was based on the ratio between SIM death registers and "Instituto Brasileiro de Geografia e Estatística"(IBGE) death estimates for the 1996-1999 period and the number of death estimated by active search in 2000-2011 $1^{13,14}$.

Population data by age and sex were taken from the 1991, 2000 and 2010 Brazilian censuses ${ }^{14}$. Intercensuses population estimates by age and sex were obtained by logarithmic interpolation of the censuses population.

In order to control the effect of age distribution variations in the period and among regions, the mortality rates (per 100 thousand inhabitants) were standardized for the Brazilian population in 2010 by sex and age using the direct method. ${ }^{14}$

To verify mortality trends during these 15 years, a linear regression model was fitted to the data. To adjust for the presence of first order autocorrelation, the residuals of the regression were modeled as a first order autoregressive process $^{15}$. With that, it was possible to test if the mortality series have a significant increasing or decreasing trend. A state space model was also fitted to the data, aiming the estimation of annual trends at every point in time ${ }^{15}$.

\section{RESULTS}

Between 1996 and 2011 it was observed a steady decrease of mortality rates for stroke for both sexes, with differences in the magnitude of decline among the regions. Age-adjusted mortality rates were higher among men for all regions. The South and Central West regions had the smallest age-adjusted rates in 1996 and 2011. In 2011, there was an important declining of age-adjusted mortality rates for both sexes, as well as a narrowing of the range among the region rates. As expected, the mortality rates became higher after correction and a higher impact of the correction can be observed among rates from the North and Northeast regions, mainly in 1996. In 2011, smaller variations of rates before and after correction can be noticed for all regions, but the higher corrections remain restricted to the North and Northeast regions (Table 2).

When rates are analyzed by age strata, it was observed an increment on mortality rates by age in both sexes, as well as a consistent and impressive decline of these rates in all age groups between 1996 and 2011 (Table 3).

The decreasing trends among all Brazilian regions were statistically significant, with higher values of decline in the Northeast and the North regions for both sexes (Table 4).

Estimates of the annual trends in stroke mortality by sex show important declining rates between 2000 and 2002, with smaller and steady values between 2006 and 2011 (Figure). 
Table 1. List of garbage codes and the proportion of redistribution to cerebrovascular disease as the cause of death.

\begin{tabular}{|c|c|c|}
\hline Group of the garbage codes & ICD-10 codes* & Proportion (\%) \\
\hline Atherosclerosis & 170.0-170.1, 170.9 & 53.90 \\
\hline Hypertension & $110, \mid 15$ & 28.67 \\
\hline Other and unspecified disorders of circulatory system & 199 & 25.68 \\
\hline Different paralytic syndrome/palsy syndrome & G80-G83 & 14.73 \\
\hline Diseases of the genitourinary system (C14) & N39.3, N40, N45-N46, N60, N84-N92, N95, N97 & 13.41 \\
\hline Osteomuscular system (C.13) & $\begin{array}{c}\text { M10-M11, M15-M25, M40, M45, M47-M48, M50-M60, } \\
\text { M65-M67, M70-M71, M75-M79, M95-M99 }\end{array}$ & 12.77 \\
\hline Mental, behavioral and neurodevelopmental disorders (C.5) & F30-F33, F34.1, F40-F48, F51-F53, F60-F99 & 10.92 \\
\hline $\begin{array}{l}\text { Diseases of the blood and blood-forming organs and } \\
\text { certain disorders involving the immune mechanism (C3) }\end{array}$ & D10-D24, D26-D31, D35-D36 & 10.45 \\
\hline DIC, acute respiratory failure & D65, 146, J96.0, J96.9 & 10.15 \\
\hline $\begin{array}{l}\text { Diseases of the eye and adnexa, diseases of the ear and } \\
\text { mastoid process (C7 \& C8) }\end{array}$ & $\begin{array}{c}\mathrm{H} 00-\mathrm{H} 02, \mathrm{H} 04-\mathrm{H} 05, \mathrm{H} 10-\mathrm{H} 11, \mathrm{H} 15-\mathrm{H} 18, \mathrm{H} 2 \mathrm{O}-\mathrm{H} 21, \\
\mathrm{H} 25-\mathrm{H} 26, \mathrm{H} 30-\mathrm{H} 31, \mathrm{H} 33-\mathrm{H} 35, \mathrm{H} 43-\mathrm{H} 47, \mathrm{H} 49-\mathrm{H} 57, \mathrm{H} 60-\mathrm{H} 61, \\
\mathrm{H} 69, \mathrm{H} 71-\mathrm{H} 74, \mathrm{H} 80-\mathrm{H} 81, \mathrm{H} 83-\mathrm{H} 93\end{array}$ & 9.95 \\
\hline Diseases of the skin and subcutaneous tissue (C12) & L03, L04, L20-L30, L45, L50, L52-L68, L70-L85, L90-L92, L98 & 9.81 \\
\hline Diseases of the digestive system (C11) & $\mathrm{K} 00-\mathrm{K} 11, \mathrm{~K} 14$ & 9.77 \\
\hline All encephalopathy and cerebral oedema & G92, G93.1-G93.6 & 8.52 \\
\hline Certain infectious and parasitic diseases (C1) & $\begin{array}{c}\text { A59-A60.0, A60.9, A63-A64, A71-A74, B07-B09, B35-B36, } \\
\text { B74.4-B74.8, B75, B85-B88, B95-B97 }\end{array}$ & 7.84 \\
\hline Pneumonitis & J69 & 7.68 \\
\hline Diseases of the nervous system (C6) & G43-G44, G47-G52, G54, G56-G58 & 6.68 \\
\hline Diseases of the respiratory system (C10) & J30, J33, J34.2, J35 & 5.88 \\
\hline $\begin{array}{l}\text { Congenital malformations, deformations and } \\
\text { chromosomal abnormalities (C17) }\end{array}$ & Q16-Q18, Q36, Q54, Q65, Q67-Q68, Q72-Q74, Q82-Q83 & 3.33 \\
\hline Embolism and thrombosis & 174,181 & 1.40 \\
\hline Cardiopaty complications and unspecified cardiac diseases & 151 & 0.73 \\
\hline
\end{tabular}

*ICD 10: International Classification of diseases - Tenth revision

Table 2. Stroke age-adjusted mortality rates before and after correction, among the Brazilian regions, in 1996 and 2011.

\begin{tabular}{|c|c|c|c|c|c|c|c|c|}
\hline \multirow{4}{*}{ Regions } & \multicolumn{8}{|c|}{ Mortality rates (per 100,000 inhabitants)* } \\
\hline & \multicolumn{4}{|c|}{ Men } & \multicolumn{4}{|c|}{ Women } \\
\hline & \multicolumn{2}{|c|}{1996} & \multicolumn{2}{|c|}{2011} & \multicolumn{2}{|c|}{1996} & \multicolumn{2}{|c|}{2011} \\
\hline & Pre & Post & Pre & Post & Pre & Post & Pre & Post \\
\hline Central west & 72.2 & 91.2 & 47.3 & 55.5 & 60.5 & 80.7 & 34.1 & 39.9 \\
\hline North & 53.0 & 115.1 & 43.1 & 61.2 & 46.5 & 102.9 & 33.7 & 45.3 \\
\hline Northeast & 53.2 & 124.3 & 49.0 & 64.0 & 42.6 & 107.8 & 36.9 & 47.8 \\
\hline South & 89.6 & 98.2 & 49.0 & 55.6 & 63.9 & 69.5 & 32.6 & 36.7 \\
\hline Southeast & 101.8 & 116.2 & 51.3 & 61.8 & 69.8 & 75.1 & 34.5 & 41.2 \\
\hline Brazil & 82.9 & 113.6 & 49.6 & 60.9 & 58.2 & 84.4 & 34.7 & 42.3 \\
\hline
\end{tabular}

*Before and after correction.

Table 3. Age-specific mortality rates from stroke, by sex, in 1996 and 2011.

\begin{tabular}{lcccc}
\hline \multirow{2}{*}{$\begin{array}{l}\text { Age group } \\
\text { (years) }\end{array}$} & \multicolumn{3}{c}{ Mortality rates (/100.000inhab) } \\
\cline { 2 - 5 } & 1996 & 2011 & 1966 & 2011 \\
\hline $30-34$ & 13.9 & 6.6 & 11.7 & 5.1 \\
\hline $35-39$ & 25.6 & 12.3 & 21.9 & 10.4 \\
\hline $40-44$ & 46.5 & 22.4 & 39.4 & 20.1 \\
\hline $45-49$ & 82.1 & 38.5 & 68.2 & 33.6 \\
\hline $50-54$ & 122.2 & 65.9 & 97.1 & 48.5 \\
\hline $55-59$ & 212.1 & 110.8 & 149.8 & 71.1 \\
\hline $60-64$ & 308.9 & 172.3 & 210.3 & 108.7 \\
\hline $65-69$ & 498.6 & 289.6 & 352.4 & 184.2 \\
\hline Total & 113.6 & 60.9 & 84.4 & 42.3 \\
\hline
\end{tabular}

Table 4. Annual linear trend of stroke mortality rates among Brazilian regions, according to the linear regression model with autoregressive errors, from 1996 to 2011.

\begin{tabular}{lcc}
\hline \multirow{2}{*}{ Brazilian regions } & \multicolumn{2}{c}{ Beta values* $^{*}$} \\
\cline { 2 - 3 } Central West & -2.823 & Female \\
\hline North & -3.425 & -3.329 \\
Northeast & -4.010 & -3.974 \\
South & -3.082 & -2.223 \\
Southeast & -3.082 & -2.262 \\
\hline
\end{tabular}

* linear regression analysis, all p-values <0.001 
According to the state space model, trend evolution in all Brazilian regions show a significant decrease in stroke mortality compared to the previous year. Among men, the decrease was more pronounced between 2000 and 2002 in the North, Northeast and Southeast Regions. In the South Region the decreasing occurred up to 2005 and in the Midwest, after an initial increase, the trend has been decreasing since 1999. In women, the decrease was accentuated in 1999 and 2000 in the North and Northeast. In the Southeast and South regions there was a steady decrease until 2005, reaching intensity decreasing from 2008. In the Midwest, the trend decreases sharply until 2002 and then stabilizes (Figure).

\section{DISCUSSION}

This study shows consistent declining trends of stroke mortality rates between 1996 and 2011. But before presenting these findings, a brief discussion of how to obtain them is described. After all, methods do matter. When studying mortality trends for the five regions of Brazil during 15 years, it is important to keep in mind that coverage and quality of cause-of-death data varies across regions and time. Valid, reliable, and comparable assessments of trends in causes of death from even the best systems are limited by coverage and quality of data issues ${ }^{16}$. The first step of a mortality analysis consists in using traditional demographic tools for correction of coverage. In this study, the number of deaths provided by the SIM were corrected by taking into account the underreporting index estimated by RIPSA and IBGE for each region and year. Without corrections for underreporting, developed regions that generally have better coverage may seem to have higher mortality rates than the poorest ones. Also, as coverage tends to improve over time, crude results may show false increases on mortality rates in the future.

Besides differences in coverage, many deaths assigned to causes that cannot or should not be considered underlying causes of death must be redistributed to a cause of death that makes sense in terms of causality or public health interpretation $^{16}$. Since the advent of the sixth revision, the ICD-10 has been used not only to code deaths but also to cover all types of medical information, including non-fatal disorders and nonspecific medical conditions ${ }^{16}$. In this study, causes such as atherosclerosis and hypertension, more plausible as risk factors than underlying cause of death, were redistributed to cerebrovascular and other cardiovascular diseases, according to preconized methods ${ }^{1}$.

Quality of data information is a proxy of socioeconomic status of a region. The less developed North and Northeast regions presented the higher proportion of correction by coverage and by redistribution of causes of deaths. The decrease in the magnitude of these corrections in 2011 may reflect improvements on information quality over time and can contribute to narrowing the data quality gap between the northern and southern regions of the country, these latter with data quality similar to developed countries ${ }^{17}$.

The North and Northeast regions also presented the higher mortality rates for both sexes, although declining trends in mortality rates can be observed among all regions of the country. The regression coefficient for the trend, presented on Table 3, indicates around $3 \%$ annual decrease on mortality during these 15 years; and the significance of this analysis indicates, with a $95 \%$ level of confidence, that this declining trend really occurred. Higher declines of mortality rates in less developed regions are generally predictable, since it is easy to have higher decreases where the health indicators are worse.

Besides socioeconomic development, the significant decreasing in stroke mortality rates may indicate the effect of cardiovascular risk factor control interventions, as well as the huge increase (450\%) on access to primary health services from 1981 to $2008^{18}$. These decreasing trends have been observed in Western nations since the 1970s and have been attributed to improved control of hypertension. As observed in developed countries, efforts towards diabetes mellitus and dyslipidemia control and smoking cessation programs,
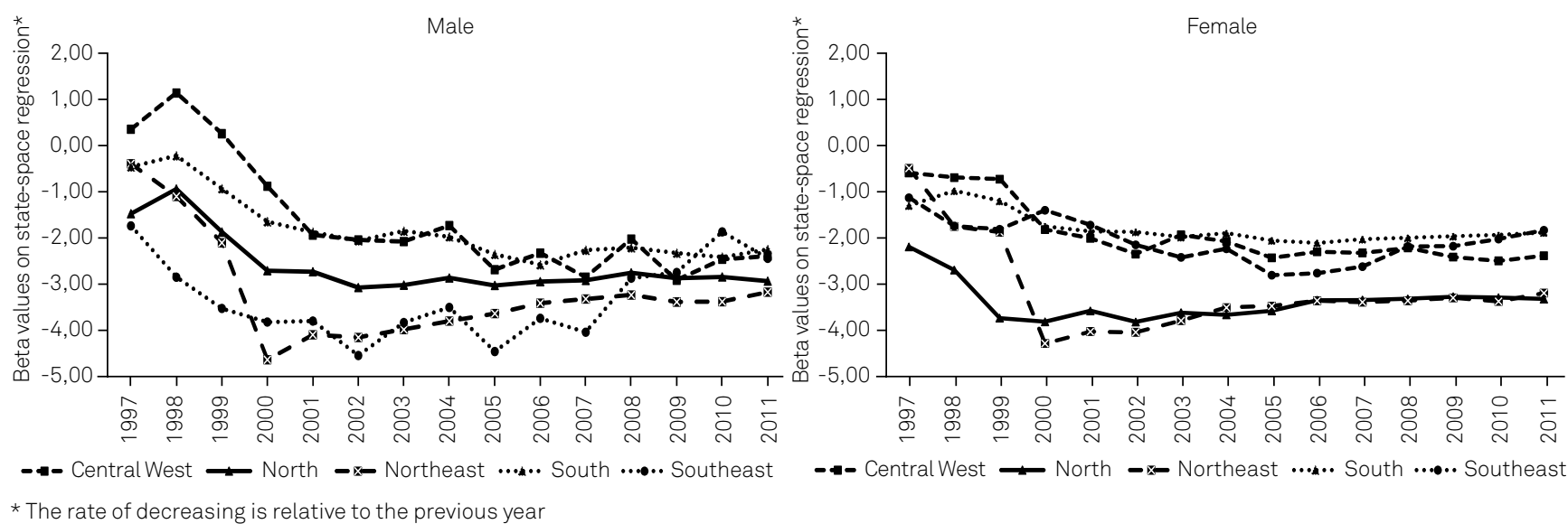

Figure. Changes in stroke mortality rates among Brazilian regions according to space-state regression model, from 1996 to 2011 
particularly in combination with treatment of hypertension, may have contributed to the decline in stroke mortality ${ }^{19}$.

Although using different methodologies, our results are consistent with the majority of published papers in the country ${ }^{5,6}$. The only dissonant note was the report of an increase in age-adjusted mortality due to cerebrovascular accidents (ICD 10, I60-I69) from 2001 to 2006, maybe because crude mortality data were not corrected ${ }^{20}$.

But public health authorities cannot fool themselves by these good trends, as much more effort still remains to be done. Besides having unequal distribution and being a recent phenomenon in Brazil, the current mortality rates are still very high. Stroke mortality has been falling rapidly in developed countries for more than 40 years ${ }^{21}$. The current burden of stroke mortality observed in the main Brazilian cities are much higher than in the United States, Canada and western European countries, and similar to what is observed in Eastern Europe and Japan. Compared to other Latin American countries, Brazil also has the highest rates, for both $\operatorname{sexes}^{22}$. Even after the impressive decline among all age strata, the current mortality rates observed in Brazilian adults and middle-aged are higher than mortality rates among elderly from developed countries ${ }^{2,3}$. All over the world, in 2005, about $40 \%$ of stroke victims were less than 70 years of age ${ }^{23}$. These results contradict the concept of stroke as a disease of the elderly and reinforce the need for cardiovascular health promotion strategies based on the life-course approach.

In order to establish preventive measures, it is important to differentiate the stroke subtypes. Cerebral ischemia is associated to atherosclerosis and can be prevented by policies aiming the reduction of cardiovascular risk factors. On the other hand, hypertension is the primary cause of hemorrhagic stroke among those aged 40 or more years (AHA/ASA Guidelines). Unfortunately, the Brazilian mortality data still lacks specificity. From 2005 to 2007, the annual average of ill-defined codes for Brazilian Capitals were very high: $31.8 \%$ of code I64.0 (stroke not specified as hemorrhagic or ischemic), $25.2 \%$ as code I61.9 (non-specified intracerebral hemorrhage) and $11.6 \%$ as code I67.8 (other cerebrovascular diseases) ${ }^{24}$. A reappraisal of stroke mortality trends in Brazil between 1979 and 2009 showed that mortality are declining in the country for all strokes subtypes, although these estimates did not considered quality differences on registry, redistribution due to garbage codes or ill-defined diseases ${ }^{25}$.

The low access to neuroimaging diagnosis may partially explain the paucity of data mortality on stroke subtypes. In São Paulo, the wealthiest State in Brazil, the changes of stroke mortality rates between 1996 and 2003 revealed an annual reduction of all types of stroke (-3.9\%) and of stroke subtypes as intracerebral hemorrhage (-3.0\%) and cerebral infarction $(-2.7 \%)$ as well as a decline of ill-defined stroke $(-7.4 \%)$ for men. The switch of ill-defined cases to stroke subtype categories due to a better clinical diagnosis may have blurred a real decline of both cerebral infarction and intracerebral hemorrhagic stroke among women ${ }^{26}$.
The high proportion of ill-defined causes and the lack of stroke subtypes classification of Brazilian death certificates are markers of low data quality, usually related to the access or the quality of medical care received by the population $^{11}$. Besides educational strategies and advocacy among doctors aiming the description of stroke subtype on death certificates, it is essential to provide referral hospitals with adequate diagnosis equipment, mainly in less developed regions. Although it have been pointed out that there is no need to increase the number of machines for computed tomography scans or magnetic resonance imaging in Brazil2 ${ }^{27}$, the availability of these diagnosis tools seems to be uneven. A national analysis of 16,879 hospital records from April 2006 to December 2007 showed that at least one CT scan were performed in only $28.6 \%$ of the stroke admissions under the Brazilian Unified National Health System. Moreover, $91.1 \%$ of these exams were performed in South and Southeast regions ${ }^{28}$.

The main strength of this study relies on the rigorous methodology and the use of all modern techniques of analysis of mortality data. But our study is limited by the lack of data of stroke incidence and case-fatality data for the country. The decline in stroke mortality rates may reflect both reduced incidence or lower case-fatality rates. Greater case-fatality rates could account for some of the increased mortality in the poorest region of the country, since quality of care varies substantially among these regions ${ }^{28}$.

Moreover, it is important to analyze the burden of stroke as a non-fatal outcome. After ten years from the first stroke, cumulative survival rates for all types of stroke were $35 \%$ among Framingham Study participants ${ }^{29}$. But how these patients survive? A recent update on stroke statistics on United States estimates that on average, every 40 seconds, someone has a stroke. At six months after stroke, $35 \%$ had depressive symptoms, $30 \%$ were unable to ambulate without assistance, and $26 \%$ were dependent in activities of daily living ${ }^{30}$. There are no estimates of the global burden of stroke in Brazil. Our country is an emerging middle-income country and our social and health structures are still inadequate to face the challenges of rehabilitation care for patients who survive to the acute phase of stroke. It will be necessary renewed emphasis on treatment of acute events as well as secondary and primary prevention through treatment and control of risk factors.

In conclusion, although good news is always welcome, health authorities must maintain and improve the efforts in the way to continue the declining trend of stroke in Brazil. The main results of this study seem to reflect the time-dependent effects of socioeconomic and health policies aiming the reduction of cardiovascular risk factors. Actions towards improving data quality must be on agenda of the public health services. It is also mandatory to discuss the best practices to treat acute stroke and decreases post-stroke morbidity. 
1. Lozano R, Naghavi M, Foreman K, Lim S, Shibuya K, Aboyans V et al. Global and regional mortality from 235 causes of death for 20 age groups in 1990 and 2010: a systematic analysis for the Global Burden of Disease Study 2010. Lancet. 2012;380(859):2095-128. doi:10.1016/S0140-6736(12)61728-0

2. Feigin VL, Lawes CM, Bennett DA, Barker-Collo SL, Parag V. Worldwide stroke incidence and early case fatality reported in 56 population-based studies: a systematic review. Lancet Neurol. 2009;8(4):355-69. doi:10.1016/S1474-4422(09)70025-0

3. Johnston SC, Mendis S, Mathers CD. Global variation in stroke burden and mortality: estimates from monitoring, surveillance and modelling. Lancet Neurol. 2009;8(4):345-54. doi:10.1016/S1474-4422(09)70023-7

4. Lolio CA, Laurenti R. Mortalidade por doença cerebrovascular em São Paulo. Rev Saúde Pública. 1986;20:436-43.

5. Mansur A P, Souza MFM, Favarato D, Avakian SD, Machado CLA, Mendes AJ et al. Stroke and ischemic heart disease mortality trends in Brazil from 1979 to 1996. Neuroepidemiology. 2003;22(3):179-83. doi:10.1159/000069893

6. Mansur AP, Favarato D. Mortality due to cardiovascular diseases in Brazil and in the metropolitan region of Sao Paulo: a 2011 update. Arq Bras Cardiol. 2012;99(2):755-61. doi:10.1590/S0066-782X2012005000061

7. Lessa I. [Epidemiology of acute cerebrovascular accidents in Salvador City: clinical aspects]. Arq Neuropsiquiatr. 1985;43(2):133-9. Portuguese. doi:10.1590/S0004-282X1985000200002

8. Minelli C, Fen LF, Minelli DPC. Stroke incidence, prognosis, 30-day, and 1-year case fatality rates in Matão, Brazil. A population-based prospective study. Stroke. 2007;38(11):2906-11. doi:10.1161/STROKEAHA.107.484139

9. Cabral NL, Gonçalves ARR, Longo AL, Moro CH, Costa G, Amaral $\mathrm{CH}$ et al .Trends in stroke incidence, mortality and case fatality rates in Joinville, Brazil: 1995-2006. J Neurol Neurosurg Psychiatry. 2009;80(7):749-54. doi:10.1136/jnnp.2008.164475

10. Ministério da Saúde (BR). Sistema de Informação em Mortalidade. Óbitos por residência por sexo, idade e causa - CID-10/Datasus Brasília, DF: Ministério da Saúde; 2014 [cited 2014 Apr]. Available from: www.datasus.gov.br

11. França E, Teixeira R, Ishitani L, Duncan BB, Cortez-Escalante $J J$, Morais Neto OL et al. Ill-defined causes of death in Brazil: a redistribution method based on the investigation of such causes. Rev Saúde Pública. 2014;48(4):671-81. doi: 10.1590/S0034-8910.2014048005146

12. Rede Intergerencial de Informações para a Saúde - RIPSA. Razão entre óbitos informados e estimados, segundo região e UF. Brasília, DF: RIPSA; 2011 [cited 2015 July 03]. Available from: http://tabnet. datasus.gov.br/cgi/idb2011/a18.htm

13. Szwarcwald CL, Morais Neto OL, Escalante JJC, Souza Junior PRB, Frias PG, Lima RB et al. Busca ativa de óbitos e nascimentos no Nordeste e na Amazônia Legal: estimação das coberturas do SIM e do SINASC nos municípios brasileiros. In: Ministério da Saúde (BR). Saúde Brasil, 2010: uma análise da situação de saúde e de evidências selecionadas de impacto de ações de vigilância em saúde. Brasília, DF: Ministério da Saúde; 2011. p. 79-98.

14. Instituto Brasileiro de Geografia e Estatística - IBGE. Available from: http://www.ibge.gov.br/home.
15. Shumway RH, Stoffer DS. Time series analysis and its applications: with R example. 3rd ed. New York: Springer; 2006.

16. Naghavi M, Makela S, Foreman K, O'Brien J, Pourmalek F, Lozano R. Algorithms for enhancing public health utility of national causes of death data. Popul Health Metr. 2010;8:9. doi:10.1186/1478-7954-8-9

17. Mikkelsen L, Phillips DE, AbouZahr C, Setel PW, Savigny D, Lozano R et al. A global assessment of civil registration and vital statistics systems: monitoring data quality and progress. Lancet. 2015;386(10001):1395-406. doi:10.1016/S0140-6736(15)60171-4

18. Paim J, Travassos C, Almeida C, Bahia L, Macinko J. The Brazilian health system: history, advances, and challenges. Lancet. 2011;377(9779):1778-97. doi:10.1016/S0140-6736(11)60054-8

19. Lackland DT, Roccella EJ, Deutsch AF, Fornage M, George $M G$, Howard $G$ et al. Factors influencing the decline in stroke mortality: a statement from the American Heart Association/American Stroke Association. Stroke. 2014;45(1):315-53. doi:10.1161/01.str.0000437068.30550.cf

20. Garritano CR, Luz PM, Pires ML, Barbosa MT, Batista KM. Analysis of the mortality trend due to cerebrovascular accident in Brazil in the XXI century. Arq Bras Cardiol. 2012;98(6):519-27. doi:10.1590/S0066-782X2012005000041

21. Klag MJ, Whelton PK, Seidler AJ. Decline in US stroke mortality: demographic trends and antihypertensive treatment. Stroke. 1989;20(1):14-21. doi:10.1161/01.STR.20.1.14

22. Lotufo PA. Stroke in Brazil: a neglected disease: editorial. Sao Paulo Med J. 2005;123(1):3-4. doi:10.1590/S1516-31802005000100001

23. Strong K, Mathers C, Bonita R. Preventing stroke: saving lives around the world. Lancet Neurol. 2007;6(2):182-7. doi:10.1016/S1474-4422(07)70031-5

24. Abreu DMX, Drumond EF, França EB, Ishitani LH, Malta CH, Machado CJ. Análise comparativa de classificações de causas evitáveis de morte em capitais brasileiras: o caso das doenças cerebrovasculares. Rev Bras Estud Popul. 2010;27(2):447-55. doi:10.1590/S0102-30982010000200014

25. Lotufo PA, Goulart AC, Fernandes TG, Benseñor IM. A reappraisal of stroke mortality trends in Brazil (1979-2009). Int J Stroke. 2013;8(3):155-63. doi:10.1111/j.1747-4949.2011.00757.x

26. Lotufo PA, Benseñor IM. Trends of stroke subtypes mortality in Sao Paulo, Brazil (1996-2003). Arq Neuropsiquiatr. 2005;63(4):951-5. doi:10.1590/S0004-282X2005000600009

27. Massaro A. Stroke in Brazil: a South America perspective. Int J Stroke. 2006;1 (2):113-5. doi:10.1111/j.1747-4949.2006.00029.x

28. Rolim CLRC, Martins M. [Quality of care for ischemic stroke in the Brazilian Unified National Health System]. Cad Saúde Pública. 2011;27(11):2106-16. Portuguese. doi:10.1590/S0102-311X2011001100004

29. Sacco RL, Wolf PA, Kannel WB, McNamara PA. Survival and recurrence following stroke: The Framingham study. Stroke. 1982;13(3):290-5. doi:10.1161/01.STR.13.3.290

30. Roger VL, Go AS, Lloyd-Jones DM, Adams RJ, Berry JD, Brown TM et al. Heart disease and stroke statistics: 2011 update: a report from the American Heart Association. Circulation. 2011;123(4):e18-209. doi:10.1161/CIR.0b013e3182009701 